\title{
Sinapine Leakage from Brassica Seeds
}

\author{
A.G. Taylor ${ }^{1}$, D.H. Paine ${ }^{2}$, and C.A. Paine ${ }^{3}$ \\ Department of Horticultural Sciences, New York State Agricultural Experiment Station, Cornell University, \\ Geneva, New York 14456
}

Additional index words. kinetics, sodium hypochlorite, cabbage, broccoli, cauliflower, Brassica sp.

\begin{abstract}
The purpose of this project was to study factors that influence the leakage rate and develop methods to enhance leakage of sinapine from Brassica seeds. Six seedlots (two seedlots of one cultivar each of cabbage ( Brassica oleracea L., Capitata group), broccoli, and cauliflower ( B. oleracea L., Botrytis group) were studied. Leakage was quantified spectrophotometrically by measuring the absorbance of the soak water at $330 \mathrm{~nm}$. The onset of sinapine leakage was determined from single seeds by the visual presence (yellow soak water) caused by soaking seeds in a biological buffer adjusted to $\mathrm{pH} 10$. The leakage pattern from heat-killed seeds of all seedlots was sigmoidal with a distinct lag phase followed by a rapid efflux and final slower rate. The duration of the lag phase and the total amount of sinapine leaked after 24 hours was not the same for all seedlots after adjusting for seed count, seed weight, or sinapine content. Therefore, another factor was responsible for differences measured in leakage. Embryos or seeds with cracked testas leaked faster than intact seeds, and the leakage pattern without testa integrity was biphasic. From these studies, we conclude that the testa was a major factor regulating sinapine leakage. Pretreating heat killed seeds, with up to $1.0 \% \mathrm{NaOCl}$ for 10 minutes, accelerated the onset of leakage. The time for 50 percent of the seeds to leak (T50) decreased as $\mathrm{NaOCl}$ concentration increased. Leakage uniformity, as measured by the standard deviation of the distribution, generally increased as NaOCl concentration increased. The sigmoidal leakage pattern from heat-killed Brassica seeds may be attributed to seedcoat cracking associated with imbibitional swelling. A NaOCl pretreatment may have increased the permeability of the testa and, thereby, enhanced the leakage rate.
\end{abstract}

Our knowledge of seed leakage is based largely on model systems studied since the early 1970s; however, first reports on seed leakage date back to the beginning of the 20th century (Priestley, 1986). The subject of leakage in seeds has been reviewed with respect to membrane functionality and mechanisms of seed aging (Bewley, 1986; Priestley, 1986).

Leakage rate of intracellular substances depends on several factors, including the specific compound, membrane condition, and presence (or absence) of morphological barriers. Seeds have been shown to leak a range of compounds, including small molecular weight materials such as ions, sugars and amino acids, UV-light absorbing substances, and macromolecules such as enzymes (Duke et al., 1983). In general, a biphasic pattern of leakage occurs with an initial rapid efflux followed by a slower leakage rate (Simon and Raja Harun, 1972). Leakage may be attributed to loss of cell membrane integrity caused by seed aging, hydration damage, or mechanical injury. Leakage is a diffusion process, and seed coverings may act as a morphological barrier to regulate or prevent leakage.

Phenolic or aromatic choline esters have been studied in seeds of the Brassicaceae (Clausen et al., 1985a. 1985b; Bouchereau et al., 1991). The predominant phenohc choline ester (PCE) was sinapine (3,5-dimethoxy-4-hydroxycinnomoylcholine) and accounted for $\approx 72 \%$ of the total PCE in Brassica oleracea. The concentration of sinapine in seedlots of oilseed rape ( $B$. campestris L. and B. napus L.) ranged from $0.4 \%$ to $1.1 \%$ of the seed weight and was independent of the glucosinolate content. The concentration of sinapine appears to be influenced by both seed production environment and genetics.

Received for publication 2 Apr. 1992. Accepted for publication 3 Nov. 1992. This research was partially supportcd by a grant from Seed Systems, Gilroy. Calif. Wc acknowledge technical assistance from G.G. Maas and P.A. Nielsen.

'Associate Professor of Seed Science and Technology. The cost of publishing this paper was defrayed in part by the payment of page charges. Under postal regulations, this paper therefore must be hereby marked advertisement solely to indicate this fact.

'Research Technician

${ }^{3}$ Former Research Technician.
Sinapine accumulated as a reserve material during seed development on the mother plant (Clausen et al., 1985a). The compound is hydrolyzed during germination by aromatic choline esterase into cinnamic acid and choline (Clausen et al., 1985b). The sinapine content was reduced by half at 4 to 7 days after germination, and little sinapine was detected in seedlings after 14 days. The plant uses choline as a constituent in membrane synthesis (Tzagoloff, 1963), and cinnamic acid is transformed into carbohydrate esters.

An aqueous solution of sinapine had an absorbance maximum of 322 and $388 \mathrm{~nm}$ at pH 7 and 10, respectively (Taylor et al., 1988). The absorbance at these wavelengths was considered to be proportional to the sinapine concentration in solution. A 26-fold increase in leakage was measured from heat-killed compared to viable seeds after an 8-h soak (Hill et al., 1988). Six seedlots from B. oleracea L. Capitata group, B. oleracea L. Botrytis group., $B$. napus L., and Erysimum hieracifolium L. were deteriorated by increasing seed moisture content to $20 \%$ (fresh weight basis) and incubating at $45 \mathrm{C}$ for $48 \mathrm{~h}$ (Taylor et al., 1991). The absorbance of the soak water was measured at $322 \mathrm{~nm}$ over time for the six lots. The general leakage pattern was similar, however, the rate and amount of leakage varied among seedlots.

The objective of this work was to study leakage of sinapine in Brassica oleracea. Variation in leakage was explored in six seedlots representing three horticultural Brassicas: cabbage, broccoli, and cauliflower. The role of the testa was examined with respect to leakage rate, and a chemical pretreatment was examined to enhance the leakage rate.

\section{Materials and Methods}

Seedlots and sinapine content. Three crop seeds were studied; cabbage, broccoli, and cauliflower. Two nontreated seedlots of each of 'Condor' cabbage, 'Citation' broccoli. and 'Snowball 76' cauliflower were provided by Harris Moran, Modesto, Calif. ('Condor' and 'Citation') and Ferry-Morse Seed Co., Modesto

Abbreviation: PCE, phenolic choline ester. 
('Snowball 76'). The average seed weight in milligrams was determined for each seedlot.

Sinapine content was determined by a method modified from Blair and Reichert (1984). Seed samples were ground in a coffee mill, and four replications of $250 \mathrm{mg}$ each were placed in $50 \mathrm{ml}$ of methanol. The mixture was incubated for $24 \mathrm{~h}$, and a $1.0 \mathrm{ml}$ aliquot was mixed with an additional $9.0 \mathrm{ml}$ of methanol. A Beckman model DU-64 scanning UV-VIS spectrophotometer (Beckman Instruments, Fullerton, Calif.) was used to measure absorbance at $330 \mathrm{~nm}$. The molar extinction coefficient of $2.14 \times 10^{4}$ (Blair and Reichert, 1984) was used to calculate the concentration of sinapine. Data were expressed as the percent sinapine based on the seed weight and as micrograms sinapine per seed.

Time course studies. The purpose of these experiments was to quantify sinapine leakage from samples of the six seedlots over time. There are several seed-related variables that may influence leakage; seed weight, seed count, and sinapine content. Three experiments were conducted in which each variable was maintained as a constant for each seedlot; $0.10 \mathrm{~g}$ seed, 25 seeds, and 1.2 $\mathrm{mg}$ sinapine, respectively.

Seed samples were first heat-killed by autoclaving at $121 \mathrm{C}$ for $20 \mathrm{~min}$ and dried under ambient conditions before leakage studies began. The general procedure used for each experiment was to place a given amount of seeds in $50 \mathrm{ml}$ distilled $\mathrm{H}_{2} \mathrm{O}$ at $25 \mathrm{C}$ and determine the absorbance at $330 \mathrm{~nm}$ at 2, 4, 6, 8, 10, 12, and $24 \mathrm{~h}$. The sipper attachment on the spectrophotometer allowed for repeated measurements from the same sample over time. There were four replications per treatment from which means and standard errors were calculated for treatment comparisons.

Seedcoat integrity and seed viability. Two experiments were conducted to study the relationships of seedcoat integrity and seed viability on leakage. The first study used cracked testa, while the second used embryos, and seedlot \#1 of broccoli 'Citation' was used for both studies. In the first study, a sample of seeds was imbibed for several hours on blotters. The testas of a small percentage of these seeds cracked and were separated from those with intact seedcoats. In the second experiment, the testas were carefully removed from a sample of imbibed seeds to expose embryos. Nonviable seeds were produced by freezing the imbibed seeds or embryos at $-70 \mathrm{C}$; samples for viable seeds or embryos were not frozen. All seeds were dried under ambient conditions before leakage experiments started. The following procedure was conducted for both experiments to achieve all combinations of seedcoat integrity with viability: Single seeds or embryos were placed in $2.0 \mathrm{ml}$ of $\mathrm{d} . \mathrm{H}_{2} \mathrm{O}$ at $25 \mathrm{C}$, and the absorbance was measured at $330 \mathrm{~nm}$ at $1,2,4,6$, and $8 \mathrm{~h}$. Absorbance readings from embryos were recorded at more frequent intervals. There were five replications per treatment, and means with standard errors were calculated.

$\mathrm{NaOCl}$ pretreatment. The purpose of this study was to quantify the influence of a pretreatment on leakage rates. Preliminary research was performed to determine if physical and/or chemical treatments could enhance the leakage rate: the most effective treatment was to soak seeds in a dilute $\mathrm{NaOC} 1$ solution before conducting leakage studies.

Solutions of $0.125 \%, 0.25 \%, 0.5 \%$, and $1.0 \% \mathrm{NaOC} 1$ were prepared from commercially available Clorox. Each solution was adjusted to $\mathrm{pH} 12$ with $\mathrm{KOH}$, and the total chlorine content was verified by titration with sodium thiosulfate (Hach Co., Loveland, Colo.). All seedlots were heat-killed as described in the time course studies. Seed samples were soaked in each of the $\mathrm{NaOCl}$ solutions for $10 \mathrm{~min}$. then rinsed and dried under ambient conditions. A 10min water soak and nonsoaked treatments were controls for each experiment.

The object of this work was to determine the onset of leakage from individual seeds rather than to measure total leakage from a sample of seeds. Therefore, a method was necessary to assess leakage on a representative sample of single seeds. Individual seeds of each treatment were placed in 96-well microtiter soak trays, and there were four replications per treatment. A biological buffer, CAPS (3-[Cyclohexylamino]-1-propanesulfonic acid) (Sigma Chemical Co., St. Louis) was adjusted to $\mathrm{pH} 10$ with $\mathrm{KOH}$ and used as the soak solution. One hundred microliters of a $75 \mathrm{~mm}$ solution was added to each well with a I2 channel pipette. Trays were visually examined on a light table at various time intervals, and the yellowed cells (indicating sinapine leakage) were counted and recorded for each tray. Cumulative frequency distributions were constructed using the means of four replications. These curves were then linearized by estimating their straight-line parameters using an iterative method to fit the data to the LOGIT model. These parameters were also used to calculate the T50 (time for 50 percent of the seeds to leak) and the leakage uniformity as measured by one standard deviation.

\section{Results}

The six seedlots studied provided representative cultivars of cabbage, broccoli, and cauliflower (Table 1). The weights ranged from 3.0 to $5.76 \mathrm{mg}$ per seed with an average of $4.25 \mathrm{mg}$. Sinapine content was highest in the two seedlots of cabbage 'Condor' $(21.2 \%)$. The other lots contained $<0.8 \%$ sinapine, and little variation was observed among cultivars. The quantity of sinapine per seed, which was influenced by both seed weight and sinapine content, ranged from 24 to $49 \mathrm{pg}$.

Time course studies. A general trend in leakage was measured from all six seedlots. There was an initial lag period followed by a rapid increase and, later, a slower rate (Fig. 1 A-C). The duration of the initial lag period varied with each seedlot; cabbage 'Condor' 1 had the shortest lag phase and the two seedlots of cauliflower 'Snowball 76' had the longest lag period. There was little variation among replications, and in many cases the standard error bars were smaller than the plot symbol.

Table 1. Seed weight and sinapine content from six Brassica seedlots.

\begin{tabular}{llcccc}
\hline \hline & & $\begin{array}{c}\text { Seed } \\
\text { wt } \\
(\mathrm{mg})\end{array}$ & $\begin{array}{c}\text { Sinapine } \\
\text { content } \\
(\%)\end{array}$ & $\begin{array}{c}\text { Sinapine } \\
\text { per seed } \\
(\mu \mathrm{g})\end{array}$ \\
\hline Crop & Cultivar & Seedlot & -4.04 & $1.20 \pm 0.02$ & 48 \\
Broccoli & Condor & 1 & 4.08 & $1.24 \pm 0.01$ & 49 \\
& & 2 & 4.32 & $0.79 \pm 0.02$ & 34 \\
Cauliflower & Citation & 1 & 3.00 & $0.80 \pm 0.04$ & 24 \\
& & 2 & 4.32 & $0.76 \pm 0.01$ & 33 \\
& Snowball 76 & 1 & 5.76 & $0.74 \pm 0.01$ & 43 \\
\hline
\end{tabular}


The time course study with the constant seed weight $(0.10 \mathrm{~g})$ revealed three groups after a $24-\mathrm{h}$ soak period; cabbage 'Condor' 1 leaked the most, cabbage 'Condor' 2 and the two broccoli 'Citation's were intermediate, and the two cauliflower 'Snowballs' leaked the least (Fig. 1 A). The second time course study was performed with a constant number of seeds (25). Leakage after 24 h from broccoli 'Citation' 2 with $3.0 \mathrm{mg}$ seeds and cauliflower 'Snowball 76' 2 with $5.76 \mathrm{mg}$ seeds showed that less leakage occurred from small than from large seeds (Fig. 1 A vs. Fig. 1 B). The third time course study was performed by maintaining a constant sinapine content $(1.2 \mathrm{mg})$. This was accomplished by adjusting the quantity of seeds in $50 \mathrm{ml} \mathrm{H}_{2} \mathrm{O}$ by their sinapine content. The total leakage was increased from seedlots with $\leq 0.8 \%$ sinapine content, and in this experiment cabbage, 'Condor' 2 leaked a similar amount as the two seedlots of cauliflower 'Snowball 76' (Fig. 1C).

Seedcoat integrity and seed liability. The influence of either cracked testa or testa removal was studied in combination with seed viability. Viable seeds with intact testa leaked negligible amounts of sinapine over $8-\mathrm{h}$, while intact nonviable seeds exhibited a 2-h lag period followed by a linear increase in leakage from 2 through $8 \mathrm{~h}$ (Fig $2 \mathrm{~A}$ and $\mathrm{B}$ ). Viable seeds with cracked testa leaked a small amount of sinapine initially with no additional
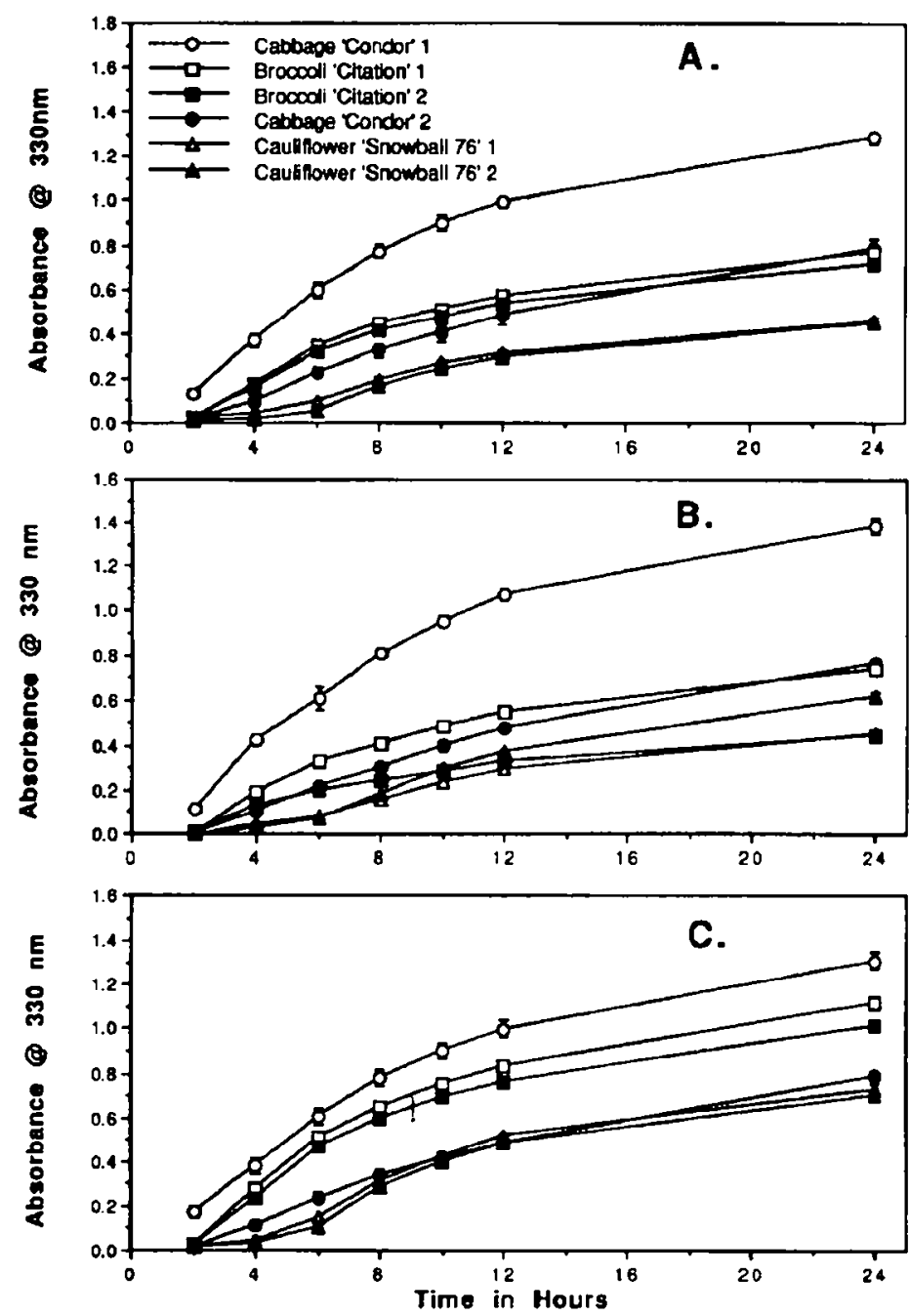

Fig. 1. Sinapine leakage from six heat-killed seedlots. Means presented with standard errors. (A) constant seed weight, (B) constant seed count, and (C) constant sinapine content. leakage after $2 \mathrm{~h}$ (Fig. 2A). Cracked nonviable seeds leaked rapidly in the first hour, and leakage continued through the duration of the 8-h study. Leakage from viable embryos showed a measurable amount of leakage in the first hour with little additional leakage up to $4 \mathrm{~h}$ (Fig. 2B). A rapid burst of leakage was measured from nonviable embryos during the first $30 \mathrm{~min}$ followed by a progressively slower rate through $2 \mathrm{~h}$.

Pretreatment with $\mathrm{NaOCl}$. The influence of $\mathrm{NaOCl}$ pretreatment on leakage rates was studied using the presence of yellow soak water as an indicator of sinapine leakage. The leakage pattern from all treatments was sigmoidal, as shown by the cumulative number of yellow cells from broccoli 'Citation' 1 (Fig. 3). Increasing the $\mathrm{NaOCl}$ concentration progressively accelerated the onset of leakage. The 10-min water soak had only a slight effect compared to the nonsoaked control. A logit transformation was performed on each data set to linearize the data, and correlation coefficients for each treatment were $\geq 0.98$ (data not shown). A decrease in $\mathrm{T} 50$ was noted as the $\mathrm{NaOCl}$ concentration increased for each seedlot (Fig. 4A). The magnitude of the decrease in T50 was greater for the slower leaking seedlots. The uniformity of leakage (one standard deviation) was more variable than the T50 data (Fig. 4B). A general linear increase in uniformity was measured in both cauliflower seedlots of Snowball. broccoli 'Citation' 1 , and cabbage 'Condor' 2 as $\mathrm{NaOCl}$ concentration increased. No significant change in slope was determined for broccoli 'Citation' 2 , and cabbage 'Condor' 1 was not calculated since there were too few data points.
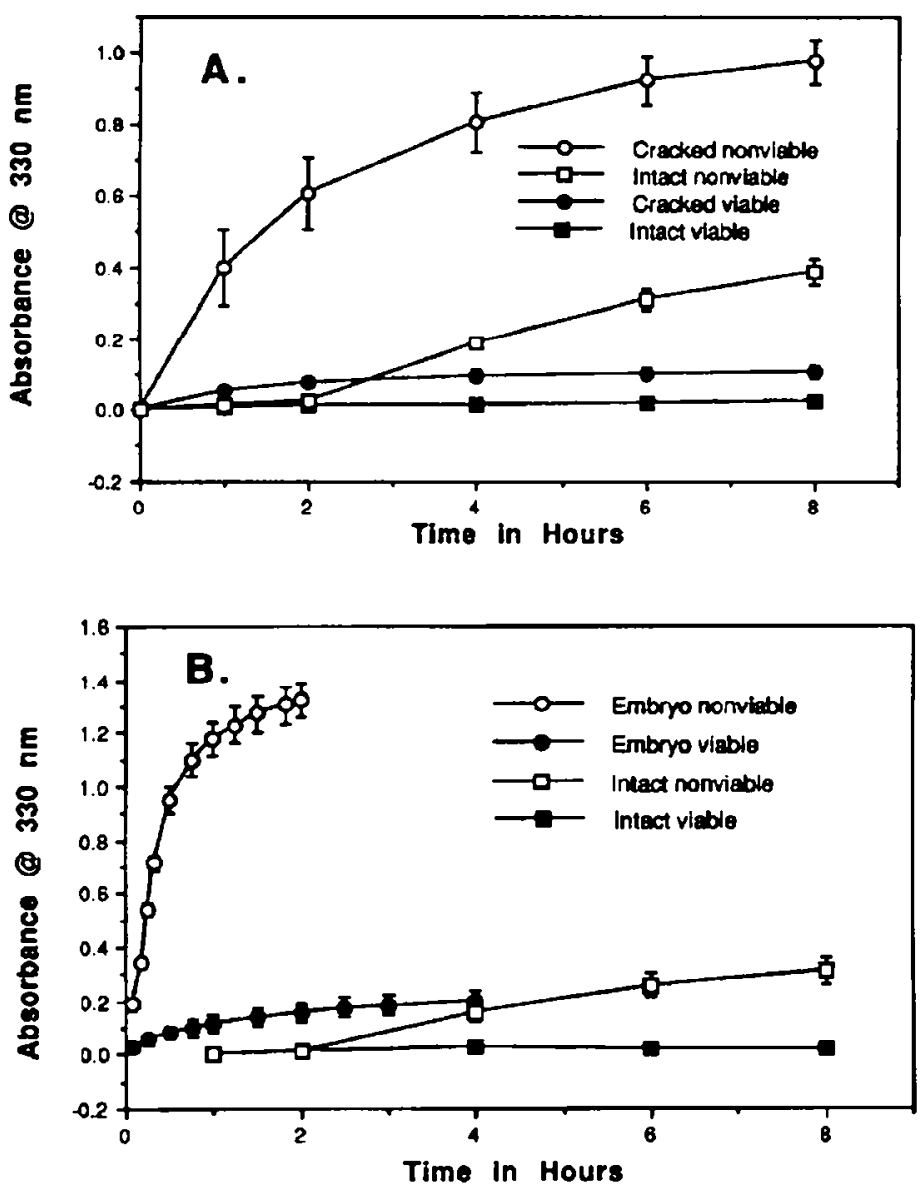

Fig. 2. Influence of testa integrity and viability on sinapine leakage. Means presented with standard errors. (A) cracked testa study and (B) embryo study (testa removed). 


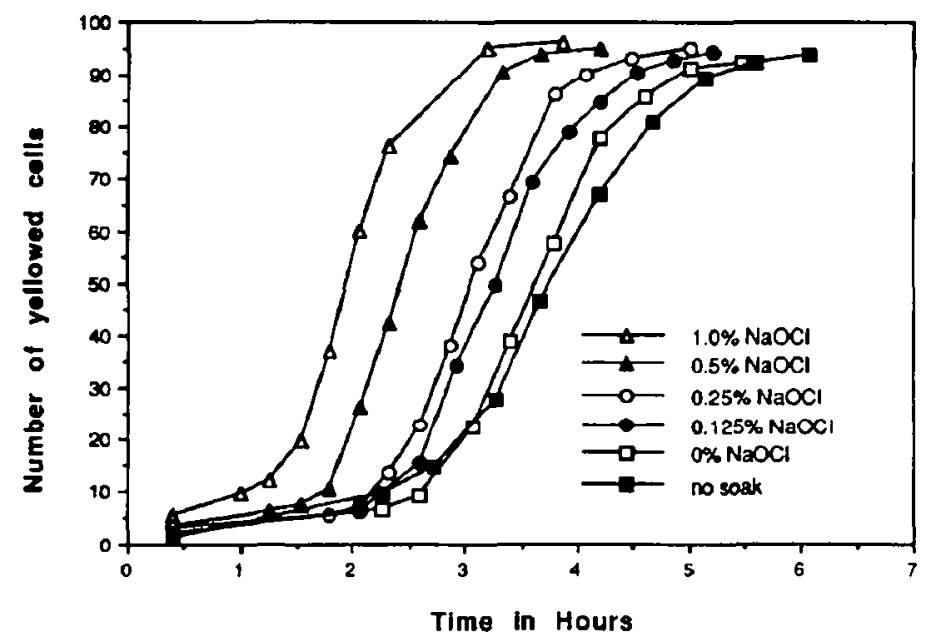

Fig. 3. Influence of $\mathrm{NaOCl}$ concentration on the onset of leakage from heat-killed broccoli 'Citation' 1.

\section{Discussion}

The leakage rate of a specific compound depends on both, environmental- and seed-related factors. Environmental factors that may influence leakage kinetics are temperature and medium water potential. Leakage rates have been shown to increase with increased temperature and water potential (Duke et al., 1983). All experiments conducted in this study were performed at ca. $25 \mathrm{C}$ and in the same water potential medium to eliminate environmental variables. Seed related variables would include seed size, sinapine content, membrane integrity, and morphological barriers.

Six seedlots of horticultural Brassica crops provided different seed sizes and sinapine contents. Seed size ranged from 3.0 to 5.8 $\mathrm{mg}$, and the sinapine content ranged from $0.74 \%$ to $1.24 \%$ (Table 1). The sinapine content of oilseed rape has been reported to range from $0.4 \%$ to $1.1 \%$ (Clausen et al., 1985a).

Loss of membrane integrity may be caused by seed aging or freezing seed high in water activity (Leopold and Vertucci, 1989). Autoclaving or freezing of imbibed seeds was performed in our study to render seeds nonviable. The final seed-related factor that may influence leakage is morphological barriers. Brassica seeds consist of an embryo with two cotyledons and an embryonic axis surrounded by the testa (Hayward, 1938). Therefore, the testa is the only natural nonliving structure that may act as a physical and/or chemical barrier to leakage.

The morphological barrier in Brassica is different from the barriers found in Phaseolus or Lactuca. Snap beans with the semihard seed characteristic do not imbibe readily when their initial moisture content is $<10 \%$ and consequently do not leak (Taylor and Dickson, 1987). In Brassica, the testa was not a barrier to water uptake, and seeds imbibe $>90 \%$ waterafter $4 \mathrm{~h}$ (Taylor et al., 1991). The endosperm, which surrounds the embryo in lettuce, acts as a semi-permeable membrane and prevents the leakage of electrolytes into the medium (Hill and Taylor, 1989). Brassica seeds do not have a specialized endosperm layer as found in lettuce.

The leakage kinetics of many compounds from seeds follows a biphasic pattern (McKersie and Senaratna, 1983). There is a rapid efflux of solutes from seeds after being transferred to the imbibing solution followed by a slower constant rate phase. In contrast, sinapine leakage from nonviable seeds with intact testa was sigmoidal (Figs. $1 \mathrm{~A}-\mathrm{C}$ and $3 \mathrm{~A}$ ). There is an initial lag phase followed by a rapid efflux and finally a lower rate. The duration of the lag phase varies with seedlot; cabbage 'Condor' 1 had the shortest and the two seedlots of cauliflower 'Snowball 76' the longest (Fig. 1A). Conducting the time course study by maintaining constant seed weight, seed count, or sinapine amount did not synchronize the leakage (Fig. 1 A-C).

The integrity of the testa was shown to have a major influence on sinapine leakage. Nonviable seeds with intact testa exhibited a 2-h lag followed by a linear phase of leakage through 8 h (Fig. 2 A and B). Nonviable seeds with cracked testa leaked appreciable amounts after $1 \mathrm{~h}$, and nonviable embryos showed a rapid efflux after only $5 \mathrm{~min}$. Leakage from nonviable seeds with cracked testa or embryos followed the biphasic pattern as previously described for other solutes. Therefore, the sigmoidal pattern was a result of the intact testa.

A technique was developed to enhance sinapine leakage but not harm the integrity of the seed. The only effective treatment found to accelerate the leakage rate was by presoaking the seeds in a dilute $\mathrm{NaOCl}$ solution. Soaking soybean [Glycine max (L.) Merr.] seeds for $20 \mathrm{~min}$ in $1.0 \% \mathrm{NaOCl}$ increased the leakage rate of sugars compared to the water control (Nordin, 1984).

A 10 min soak in $1.0 \% \mathrm{NaOCl}$ is commonly used to surface sterilize seeds (Guthrie, 1978). The germicidal properties of $\mathrm{NaOCl}$ are dependent on $\mathrm{pH}$ and, therefore, the solution was adjusted to $\mathrm{pH} 12$ for the available chlorine to be in the hypochlorite ion form (Abdul-Baki and Moore, 1979). The available chlorine content of commercial Clorox bleach was found to decrease over time, and determination of available chlorine by titration was performed routinely.

The time to onset of sinapine leakage was shortened as the $\mathrm{NaOCl}$ concentration increased (Fig. 3A). The rate and uniformity
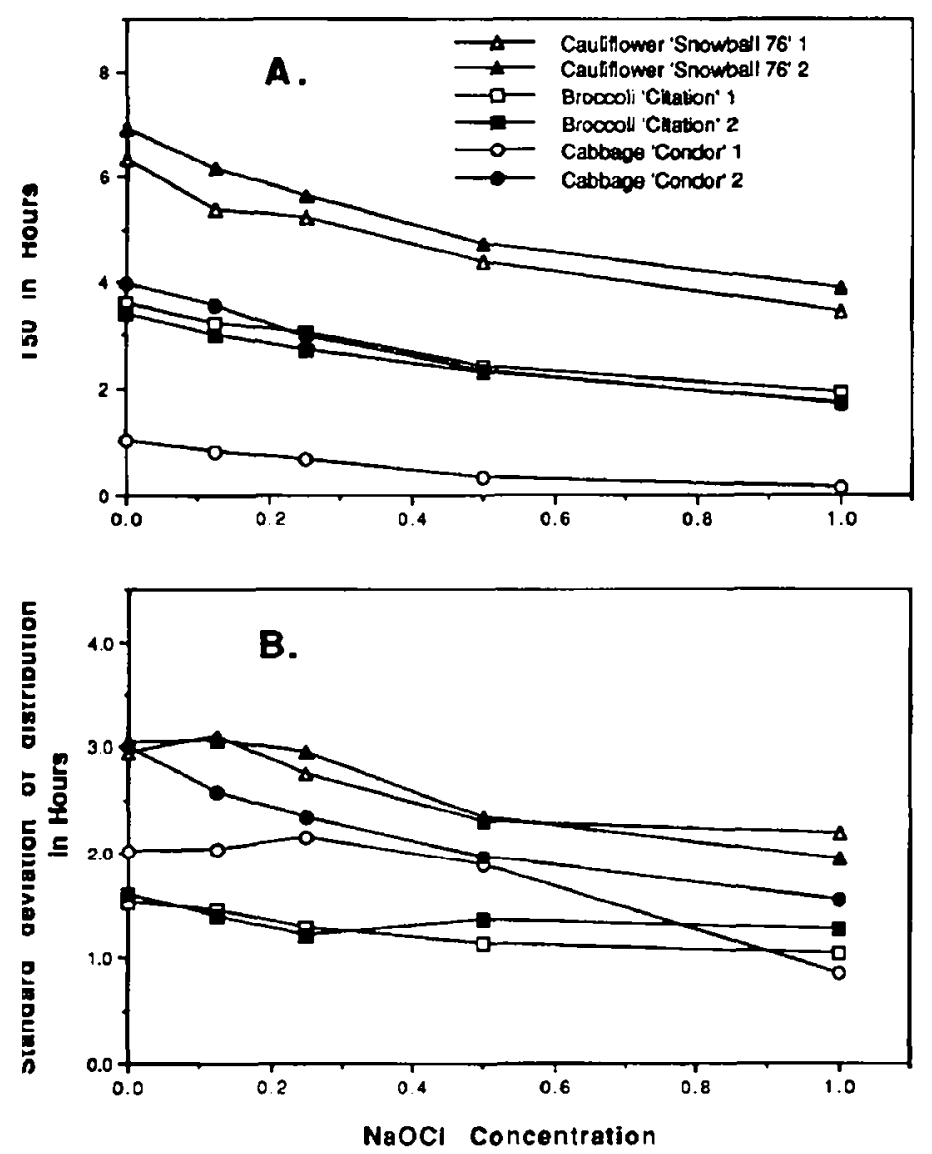

ig. 4. Influence of $\mathrm{NaOCl}$ concentration on the rate and uniformity of sinapine leakage. (A) T50 and (B) sD. 
of leakage as measured by the T50 and the standard deviation of the distribution were influenced by $\mathrm{NaOCl}$ concentration. A consistent decrease in T50 was determined for all seedlots as $\mathrm{NaOCl}$ concentration increased (Fig. 4A). The greatest response was measured by the slow leaking seedlots (cauliflower 'Snowball 76'). The data on uniformity of leakage were more variable than the T50s. yet a general linear increase in uniformity was measured as $\mathrm{NaOCl}$ increased for all seedlots, except for broccoli 'Citation' 2. Thus, the brief $\mathrm{NaOCl}$ pretreatment in all cases generally synchronized and increased the rate of leakage.

The sigmoidal leakage pattern may be attributed to seedcoat cracking that accompanies imbibitional swelling. Seedcoat cracking in Brassica is a normal process and precedes radicle emergence by several hours (Schopper and Plachy, 1984). Leakage generally occurs in the early stages of germination, while visible testa cracking occurs later $(>10 \mathrm{~h})$. Sufficient seedcoat cracking may occur during swelling to allow sinapine leakage before visible breakage. Therefore, seedcoat cracking may, in part, be responsible for the sigmoidal leakage pattern.

In a separate study, heat-killed seeds were imbibed in $75 \mathrm{~mm}$ CAPS solution adjusted to $\mathrm{pH} 10$ in soak trays and selected for leakage over time by visual inspection of the soak water. Small cracks were observed on the testa with scanning electron microscopy (SEM) in less than half of the leaking seeds, while only a small portion of nonleaking seeds revealed cracks. Therefore, strong evidence was not found to support that leakage was caused by seedcoat cracking (Beresniewicz and Taylor, unpublished data).

The mechanism of $\mathrm{NaOCl}$ on leakage is unknown. The $\mathrm{NaOCl}$ pretreatment may increase seedcoat permeability by altering the chemical components of the testa or physical characteristics of cells within the testa. The leakage study in soak trays was repeated with seeds pretreated with $\mathrm{NaOCl}$, as described above. The $\mathrm{NaOCl}$ did not appear to abrade the external surface of the testa, and few cracks were observed with SEM from either leaking or nonleaking seeds. Therefore, the $\mathrm{NaOCl}$ pretreatment appears to alter the permeability of the testa rather than the physical integrity.

In conclusion, a sigmoidal pattern of sinapine leakage was measured from nonviable Brassica seeds with intact testas. The duration of the initial lag phase varies among seedlots and may be attributed to the testa permeability of the individual seedlots and individual seeds within a seedlot. Nonviable seeds with cracked testas or embryos exhibit the typical biphasic pattern of leakage. The sigmoidal pattern was attributed to presence of the testa. A pretreatment with up to 1.0 percent $\mathrm{NaOCl}$ for 10 min increased the rate of leakage and generally increased the uniformity of leakage.

\section{Literature Cited}

Abdul-Baki, A.A. and G.M. Moore. 1979. Seed disinfection with hypochlorites: A selected literature review of hypochlorite chemistry and definition of terms. J. Seed Technol. 4(1):43-56.
Bewley, J.D. 1986. Membrane changes in seeds as related to germination and the perturbations resulting from deterioration in storage, p. 27-45. In: M.B. McDonald and C.J. Nelson (eds.). Physiology of seed deterioration, Crop Sci. Soc. Amer. Spec. Pub. no. 11, Crop Sci. Soc. Amer., Madison, Wis.

Blair, R. and R.D. Reichert. 1984. Carbohydrate and phenolic constituents in a comprehensive range of rapeseed and canola fractions: Nutritional significance for animals. J. Sci. Food Agr. 35:29-35.

Bouchereau, A., J. Hamelin, I. Lamour, M. Renard, and F. Larher. 1991. Distribution of sinapine and related compounds in seeds of Brassica and allied genera. Phytochemistry 30(6):1873-1881.

Clausen, S., L.M. Larsen, A. Ploger, and H. Sorensen. 1985a. Aromatic choline esterase and catabolism of aromatic choline esters, p. 138-147. In: H. Sorensen (ed.). Advances in the production and utilization of cruciferous crops. Martinus Nijhoff/W. Junk, Dordrecht.

Clausen, S., L.M. Larsen, A. Ploger, and H. Sorensen. 1985b. Aromatic choline esters in rapeseed, p. 61-72 In: H. Sorensen (ed.). Advances in the production and utilization of cruciferous crops. Martinus Nijhoff/W. Junk, Dordrecht.

Duke, S.H., G. Kakefuda, and T.M. Harvey. 1983. Differential leakage of intracellular substances from imbibing soybean seeds. Plant Physiol. 72:1919-924.

Guthrie, J.W. 1978. Standardizing the use of sodium hypochlorite as a seed pretreatment. Assn. Seed Anal. Nwsl. 52(2):41-99.

Hayward, H.E. 1938. The structure of economic plants. The Macmillan Co., New York.

Hill, H.J. and A.G. Taylor. 1989. Relationship between viability. endosperm integrity, and imbibed lettuce seed density and leakage. HortScience 24:814-816.

Hill, H.J., A.G. Taylor, and X.L. Huang. 1988. Seed viability determinations in cabbage utilizing sinapine leakage and electrical conductivity measurements. J. Expt. Bot. 39:1439-1447.

Leopold, A.C. and C.W. Vertucci. 1989. Moisture as a regulator of physiological reaction in seeds, p. 51-48. In: P.C. Stanwood and M.B. McDonald (eds.). Seed Moisture. Crop Sci. Soc. Amer., Madison, Wis. McKersie, B.D. and T. Senaratna. 1983. Membrane structure in germinating seeds, p. 29-52 In: C. Nozzolillo, P. J. Lea, and F.A. Loewus (eds.). Mobilization of reserves in germination. Rec. Adv. Phytochem. vol. 17. Nordin, P. 1984. Preferential leaching of pinitol from soybeans during imbibition. Plant Physiol. 76:313-315.

Priestley, D.A. 1986. Seed aging: Implications for seed storage and persistence in the soil. Cornstock Publ. Assoc., Ithaca.

Schopfer, P. and C. Plachy. 1984. Control of seed germination by abscisic acid IT. Effect on embryo water intake in Brassica napus L. Plant Physiol. 76:155-160.

Simon, E.W. and R.M. Raja Harun. 1972. Leakage during seed imbibition. J. Expt. Bot. 23:1076-1085.

Taylor, A.G. and M.H. Dickson. 1987. Seed coat permeability in semihard snap bean seeds: Its influence on imbibitional chilling injury. J. Hort. Sci. 62(2):183-189.

Taylor, A.G., X.L. Huang, and H.J. Hill. 1988. Sinapine leakage from non-viable cabbage seeds. J. Expt. Bot. 39:1433-1438.

Taylor, A.G., T.G. Min, and C.A. Mallaber. 1991. Seed coating system to upgrade Brassicaceae seed quality by exploiting sinapine leakage. Seed Sci. \& Technol. 19:423-433.

Tzagoloff, A. 1963. Metabolism of sinapine in mustard plants. I. Degradation of sinapine to sinapic acid and choline. Plant Physiol. 38:202-206. 